Diánoia, vol. 3, no. 3, 1957

\title{
LAS BASES DE LA COSMOLOGÍA DE ANAXÁGORAS
}

(Fragmento)

Con idénticos caracteres se nos presenta, por lo que toca a la cuestión del vacío, el pensamiento de Anaxágoras. También para éste, tanto como para Empédocles, es imposible el que pueda darse un vacío en la realidad. ${ }^{1}$ Pero no sólo en este punto concuerdan el uno y el otro. Las dificultades de una generación y una destrucción concebidas en íntima relación con lo que no es, con la nada, encuentran una misma solución en ambos pensadores. Evidente es que tal solución, como ya se ha apuntado repetidamente, no es su obra propia; antes bien, no representa otra cosa más que la herencia que de Parménides reciben y que ellos aceptan sin vacilar. Ya cuando nos ocupamos de este asunto, en relación a Empédocles, hicimos notar la inmensa similitud, incluso terminológica, que ofrecía el planteamiento que de tal problema hace el filósofo de Agrigento con el que de él hace el eleata. Por eso, no es de sorprender el que ahora encontremos en Anaxágoras el mismo hecho repetido una vez más.

Dentro de la brevedad del único de los fragmentos de su obra en que se ocupa de lo que puedan ser la generación y la destrucción, se nos vuelven a hacer presentes los mismos elementos condicionantes, vuelve a resonar el mismo leitmotiv eleático. ${ }^{2}$ Una generación que tenga como punto de partida el no ente es tan imposible como una destrucción que conduzca a él. ${ }^{3}$ Por eso nos dirá Anaxágoras que los griegos no les dan un uso correcto a estos términos, pues de hecho ninguna cosa $(\chi \varrho \tilde{\eta} \mu \alpha)$ se destruye o genera.* En el reino de la verdad que trata de establecer no tiene cabida alguna, al igual que en el caso de Parménides, un "mundo $u$ orden engañoso de palabras". " La razón es muy simple. Todas las efectivas transformaciones de la realidad que pudieran ser atribuídas a la generación y a la destrucción no vienen a ser sino el resultado de una mezcla ( $\sigma u ́ \mu \mu\left(\xi_{15}\right.$ ) y separación

1 Véase Arist., de caelo, $\Delta, 2,309 \mathrm{a} 19$; de respir., 2, 470b 30.

2 Anaxágoras, B 17.

3 Al contrario de lo que sucede con Empédocles, no encontramos desarrollada esta tesis en ninguno de los fragmentos de Anaxágoras, y tenemos que recurrir a lo que sobre este punto nos dicen los testimonios indirectos. Véase Kranz, Wortindex, págs. 145b-146a. Entre los testimonios más importantes tenemos los siguientes: Arist., phys., A, 4, 187a 27-29; Simpl., phys., 460, 4; Aecio, I, 3, 5.

4 Anaxágoras, B 17. Cf. F. Heinimann, Nomos und Physis, Verlag Friedrich Reinbardt, Basel, 1945; pág. 49, n. 16.

5 Parménides, B 8, 52. Véase nuestro artículo "El no ente en la filosofía de Parménides", Diánoia, I, 1955; pág. 113. 


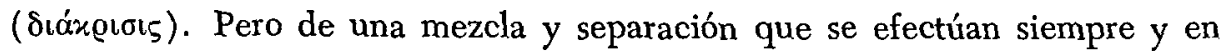
todo caso a partir de cosas que ya son. ${ }^{6} \mathrm{Y}$ tales nombres son los que se deben aplicar a dichas transformaciones si se quiere hablar correctamente, con expresión justa y fiel que no sea mera palabrería sin sentido. ${ }^{7}$ Claro está, por otra parte, que su aplicación depende de la particular perspectiva en que nos coloquemos; pues lo que por un lado puede verse como mezcla, por el otro puede aparecer como separación o a la inversa, sin desdoro, en ambos casos, de que la apreciación sea correcta. ${ }^{8}$

El significado que cobra el verbo vouí̧ııv, en el fragmento 17 de Anaxágoras, es el mismo que le adscribe Empédocles. ${ }^{9}$ En uno y otro caso sirve para designar simplemente el "uso del lenguaje". ${ }^{10}$ Pero Anaxágoras no hace la menor concesión en cuanto a este uso. Es cierto que Empédocles ha rebasado ya definitivamente la etapa del pensamiento arcaico en que nombre y concepto se identifican y que le parece legítimo designar una y la misma cosa con nombres que, en rigor, se excluyen; ${ }^{11}$ no obstante, en el caso de Anaxágoras, esto no sucede más que a medias. ${ }^{12}$ Un nombre divino como el de Iris puede aplicarse también a un fenómeno; ${ }^{13}$ pero "generación" y "des: trucción" no son sino signos vacuos que nada dicen y cuyo uso no tiene sentido una vez que hayamos comprendido cabalmente lo que es la realidad. Sólo el vivir en el error es lo que paradójicamente les da sentido. Tal apreciación, basada en los brillantes análisis de Heinimann, parécenos irrefutable; en todo caso, dado que para nosotros no hay otro Anaxágoras más auténtico que el que se nos revela en los pocos fragmentos que de su obra se conservan, es posible afirmar que en ningún momento ha hecho uso de tales términos para aludir a la mezcla y la separación; ya que en el fragmento sexto, $\gamma \varepsilon \varepsilon \varepsilon ́ \sigma \vartheta a$ tiene una acepción completamente distinta, como es obvio, y no

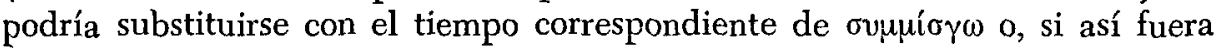

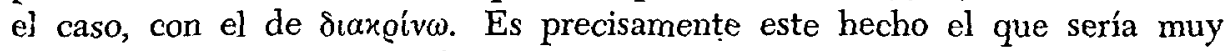
difícil de explicar en otra forma.

Ahora bien, en relación con todo lo anterior, ocurre algo que menester

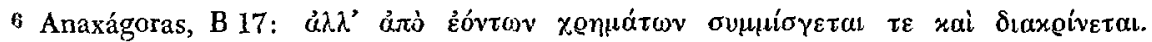
Cf. Arist., phys., A, 4, 187a 35-37.

7 Cf. Heinimann, op. cit., pág. 49: "Wie sehr daneben dennoch auch bei Anaxagoras Name und Begriff gleichgesetz werden, zeigt sein Fragment B 17..."

8 Esto se hace patente si comparamos, por ejemplo, los fragmentos 13 y 17 de Anaxágoras; puesto que la "generación" de las cosas puede deberse no sólo a una mezcla, como nos lo dice el fragmento 17 , sino también a una separación a partir de la mezcla originaria, según lo explica el fragmento 13.

9 CE. Heinimann, op. cit., pág. 49, n. 15; pág. 83.

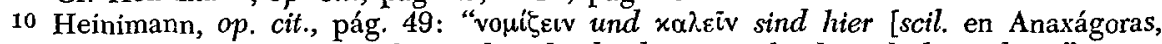
B 17] beinahe synonym verwendet, indem beide den Sprachgebrauch bezeichnen".

11 Véase Heinimann, op. cit., pág. 49. Cf. nuestro ensayo "La Metafísica de Empédocles", Diánoia, II, 1956; págs. 172-175.

12 Cf. Heinimann, op. cit., pág. 49.

13 Anaxágoras, B 19. 
es no pasar por alto. En efecto, esta repetida repudiación de una generación y una destrucción consideradas en íntima relación con lo que no es, puede parecer bien extraña si se reflexiona en que hasta este entonces a ningún griego se le ha ocurrido pensar que tal sea su carácter en cuanto procesos reales, afirmando que algo pueda efectivamente generarse a partir de lo que no es o destruirse por completo, esto es, aniquilarse o reducirse a lo que no es. Hasta ahora, sólo un pensador ha establecido que la generación tanto como la destrucción implican necesaria y forzosamente el no ente; pero el fin que perseguía al hacer esto era el tratar de reducir al absurdo la pretensión de validez de todo mecanismo explicativo de los cambios que sufre la realidad. El hecho es comprensible. Para Parménides la realidad consistía única y exclusivamente en lo que es, en el ente. De este modo, la realidad no podía, en lo absoluto, sufrir ninguna clase de transformación, fuera ésta la que fuere; puesto que eso equivaldría a suponer algo distinto del ente, de lo cual fuera éste una transformación o en lo cual pudiera transformarse. Pero, en la realidad nada distinto del ente puede darse. Todo lo que de él difiriera no vendría a ser sino no ente. De aquí que aceptar la generación y la destrucción como algo real equivalga, para Parménides, a admitir el no ente. Con todo, estas razones del eleata no parecen ser las mismas que las de un Anaxágoras o un Empédocles. En efecto, la realidad para estos dos últimos pen: sadores no es una, homogénea, sino, por el contrario, algo heterogéneo y diversificado. ${ }^{14} \mathrm{Y}$ es gracias precisamente a esta heterogeneidad como se hace posible explicar las continuas transformaciones que se dan en su seno y que nos revelan nuestras percepciones. El problema, en consecuencia, se traslada a un campo más general. Ahora de lo que se trata es de evidenciar que, entre esa realidad heterogénea y lo que de ningún modo existe, no hay ni puede haber tránsito alguno, puesto que, como nos decía Empédocles, eso es impo: sible e impensable. ${ }^{15}$

La aceptación de la heterogeneidad de la realidad ha permitido, como consecuencia, aceptar una serie de transformaciones de la misma, que, para Parménides, no hubieran tenido otro valor que el de un mero espejismo lingüístico. Pero, no obstante, la impensabilidad de lo que no es, al par que la racionalidad de la realidad, las dos grandes tesis conjugadas del eleata, siguen conservando todo su valor en las doctrinas de Empédocles y Anaxágoras. Esta herencia es lo que condiciona justamente ese repetido y vehemente

14 Parménides ha sido el primero, en la historia del pensamiento griego, en darnos un concepto más elaborado de la "unidad" al vincularla con la homogeneidad. Si la realidad es una, ello obedece a que es homogénea. Todos los argumentos de Parménides para probar su unidad numérica descansan, en último resultado, sobre esta base. Cf. W. A. Heidel, La edad heroica de la ciencia, trad. de A. de Mondolfo, Espasa Calpe Argentina, Buenos Aires, 1946; pág. 134.

15 Empédocles, B 12, 1-2. Véase nuestro ensayo "La Metafísica de Empédocles", Diánoia, II, 1956; pág. 175, n. 45. 
repùdio de toda génesis y destrucción que hubieran de implicar la no realidad. Al mismo tiempo, el establecimiento de la heterogeneidad de lo que es posibilita el manejo de un concepto analógico del no ente. Ya, cuando nos ocupamos de Empédocles, hicimos notar que la comparación de un 'estado de cosas anterior con un posterior permitía considerar ese estado anterior, del cual deriva el posterior, como lo que no es aquél que surge a partir de él. Vimos también cómo Empédocles distinguía cuidadosamente, por lo que toca a la terminología, entre lo que no es tomado en este sentido y lo que no es en sentido absoluto. El hecho es posible volverlo a encontrar en Anaxágoras, así sea de modo esquemático; pues, en efecto, cuando en el fragmento 12 se nos dice que el Nous ordena o gobierna todas las cosas, ${ }^{16}$ estas cosas se especifican con arreglo a una disposición temporal. Por una parte, el Nous rige el modo en que debían llegar a ser y el modo como fueron las cosas que ahora no son, por otra, rige también todas las que ahora son, tanto como el modo en que serán. ${ }^{17}$ Aquí, como en el texto paralelo de Empédocles, ${ }^{18}$ resalta con toda claridad el hecho de que, en relación a un estado presente, puede hablarse de cosas que ya no son o de cosas que serán, a causa justamente del distinto modo que tienen de darse unas y otras a lo largo del devenir de la realidad. Los "modos", por así decirlo, en que se nos va presentando paulatinamente la realidad son, sólo que son de una manera distinta de como es la realidad en su totalidad. Son una vez esto y otra vez aquello, dejan de ser esto o aquello; pero la realidad es siempre: siempre es igual a sí misma. Tenemos, en consecuencia, dos formas de ser: el ser esto o aquello y el ser eternamente aquello que se es; pues, para Anaxágoras, tal como para Parménides y Empédocles, ser es lo mismo que ser así, equivale a ser tal o cual, con determinadas características, que, en nuestro caso, son unas para la realidad en su conjunto y otras para sus "modos". ${ }^{19}$

De esta manera, por obra de la síntesis que realizan Empédocles y Anaxágoras, se inicia la historia de la analogia entis; el ingrediente sobre el cual ha de girar el grueso de todas las doctrinas metafísicas del futuro. Muchos

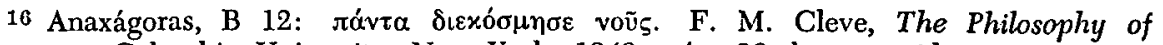
Anaxagoras, Columbia University, New York, 1949; pág. 26, ha sostenido que es impo-

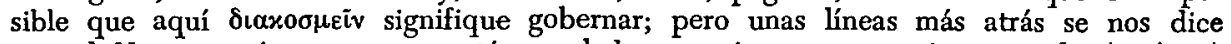
que el Nous, gracias a que no está mezclado con ninguna cosa, tiene mando (roútos) sobre ellas y, como se ve por el texto citado, su gobierno se extiende a todas las cosas y no meramente a unas cuantas. Cf. Platón, Cratilo 413c y Arist., de anima, A. 2, 405a 15. Sobre esto véase A. Emminger, Die vorsokratischen Philosophen nach den Berichten des Aristoteles, A. Stuber, Würzburg, 1878; pág. 174, n. 305.

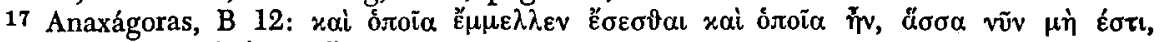

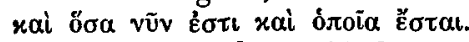

18 Empédocles, B 21, 9.

19 Cf. con lo que nos dice Joseph Owens, The doctrine of being in the Aristotelian Metaphysics, Pontifical Institute of Mediaeval Studies, Toronto, 1951; pág. 236, en relación a Aristóteles: "... for the Stagirit, 'to be a definite abiding something' is simply to be". 
siglos faltan todavía para que Cayetano acuñe su célebre fórmula: "Su conocimiento (scil. de la doctrina de la analogía) es tan necesario, que sin él nadie puede estudiar Metafísica"; ${ }^{20}$ pero ya aquí escuchamos sus primeros balbuceos. El ser es análogo; la realidad total es, al igual que es. cada uno de sus "modos" y, sin embargo, no son en la misma forma. La una -basta recordarlo- no se transforma, las cosas particulares sí. Tales transformaciones, con todo, no implican en ninguna forma el no ente absoluto. Nada surge, como ya hemos visto, a partir de él ni nada se destruye por completo. Lo que no es, el no ente, adquiere consecuentemente un doble sentido. Decir que toda la realidad no es no significa lo mismo que decir que no es ya uno cualquiera de sus "modos", aunque, en un cierto sentido, sea lo mismo. $\mathrm{El}$ uso de un concepto aún no dilucidado de la analogia entis. se manifiesta aquí de una manera muy nítida. ${ }^{21}$ La generación y la destrucción sólo pueden entenderse si se relacionan con un tipo de no ente que sea la negación de la realidad entera. De aquí su imposibilidad y su falta de sentido. De aquí que el equívoco más peligroso que debemos evitar sea el de relacionarlas con las transformaciones particulares de la realidad, con ese dejar de ser de tales "modos"; pues, en efecto, las transformaciones no son, en el fondo, sino obra de la mezcla y la separación. Tal tesis de Anaxágoras, ${ }^{22}$ como lo testimonia Aecio, ${ }^{23}$ ha dejado sentir un poderoso influjo más allá del campo estrictamente filosófico. Eurípides nos repetirá lo mismo en un fragmento de su drama perdido Crisipo. ${ }^{24}$ Pero en Ovidio incluso podemos encontrar algo semejante. ${ }^{25}$ Ambos escritores dan fiel testimonio del nuevo y esencial

20 Thomas de Vio Cardinalis Caietanus, de Nominum Analogia, ed. de Maria, Roma, 1907; cap. I, pág. 249; "Est siquidem eius notitia adeo necessaria ut sine illa non possit metaphysicam quispiam discere. ..”.

21 De hecho sigue siendo válida la apreciación de Höffding, Der Begriff der Analogie, O. R. Reisland, Leipzig, 1924; pág. 41: "Die Begriffe Analogie und Analogieschluss sind zuerst mit Klarheit von Aristoteles hervorgehoben worden".

22 Zeller tiene razón en considerar esta tesis como fundamental en el pensamiento de Anaxágoras. Véase Zeller, Die Philosophie der Griechen, O, R. Reisland, Leipzig, 6. Aufl., 1920; I, 2, págs. 1206; 1208 n. 1; 1258-1259.

23 Aecio, V, 19, 23.

24 Eurípides, frag. 839 (Nauck):

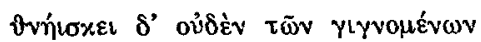

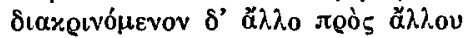

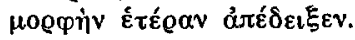

Véase Vitruvio, De Architectura, ed. Rose Müller-Strübing, Leipzig, 1899; VIII, praef. $\$ 1$ : "Euripides auditor Anaxagorae, quem philosophum Atenienses scenicum appellaverunt..."

25 Ovidio, Met., 15, 254:

Nec perit in tanto quidquam, mihi credite mundo;

Sed variat, faciemque novat, nascite vocatur

Incipere esse aliud, quam quod fuit ante, morique

Desinere illud idem...................... 
carácter que han cobrado, dentro del pensamiento filosófico, la generación y la destrucción inmediatamente después de Parménides. La tesis de la homogeneidad de lo que es se ha abandonado; pero la realidad sigue concibiéndose en un plano de total e irrebasable alteridad frente a lo que no es en absoluto.

La afirmación de la indestructibilidad de lo que existe, conjugada con la tesis de que en todo hay una porción de todo, le permitirá elaborar a Anaxágoras un concepto novísimo de la constitución de la realidad. Ahora bien, nadie de los que han entrado en contacto con la filosofía griega desconoce las terribles dificultades con que se tropieza al tratar de comprender de modo claro y exhaustivo el pensamiento de Anaxágoras. Aquí no nos interesa destacar las causas y los factores que las han originado, sino sólo establecer un hecho. Un hecho que, por otra parte, atestiguan suficientemente los numerosos intentos de reconstrucción que han tenido a Anaxágoras como objeto y que, en la gran mayoría de los casos, no han logrado plenamente su propósito. Ya H. H. Joachìm, refiriéndose a las interpretaciones de Burnet y Giusani, nos decía que ninguna de las dos exṕlica de modo satisfactorio todos los fragmentos de este filósofo. ${ }^{26}$ Lo mismo, sin embargo, podría afirmarse de otras muchas exposiciones, sin exceptuar -claro está- la que aquí vamos a emprender. Debemos advertir también que nuestro propósito no es el de ocuparnos con la doctrina entera de Anaxágoras, sino con ciertos y definidos temas que nos ayuden a precisar su postura frente a la cuestión del no ente. El más importante de ellos es, sin duda alguna, aquel que se refiere a los modos en que está constituída la realidad. Sólo que su aclaración deberá partir ineludiblemente de lo que sobre esta teoría nos dicen los testimonios indirectos. Las razones de tal proceder esperamos que se harán visi- bles más adelante; pero ya podemos afirmar que a menos que se les interprete correctamente, no habrá posibilidad alguna de moverse en terreno firme.

Ahora bien, los componentes de la realidad, haciendo salvedad del Nous,

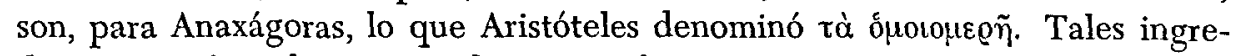
dientes, según sabemos por la misma fuente, ocupan idéntico puesto en la doctrina de Anaxágoras que el Aire, la Tierra, el Agua y el Fuego en la de Empédocles. Así como estos últimos pueden caracterizarse como elementos

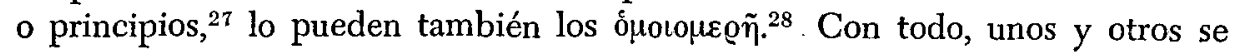

26 Harold H. Joachim, Aristotle's On Coming-to-be and Passing-away. A revised text with Introduction and Comentary, Clarendon Press, Oxford, 1922; pág. 65.

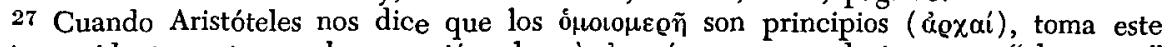

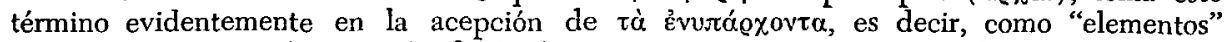
( $\sigma \tau 0 \iota x \varepsilon \tilde{\alpha} \alpha$ ), y no en la acepción de éxtós, que sirve precisamente para distinguir principio y elemento en la filosofía aristotélica. Véase Arist., Metaph., $\Lambda, 3,1070 \mathrm{~b} 22-24 ;$ Metaph., $\Delta$, 2, 1014a 26-27; Metaph., N, 3, 1091b 11. Tal es la razón por la cual Aristóteles, al contraponer el Nous de Anaxágoras a la $\Phi$ i $\lambda i \alpha$ de Empédocles, nos diga que el primero es un principio, en tanto que la segunda es un elemento, basándose en su suposición de que el Nous, a diferencia del Amor, es una causa eficiente externa.

28 Véase Arist., de caelo, $\Gamma, 3,302 \mathrm{a} 28-32$; de gen. et corr., A, 1, 314a 18-19 y 
distinguen ya de inmediato en virtud de su número. Los “elementos” de Anaxágoras, para usar la terminología aristotélica, son infinitos. ${ }^{29}$ El sentido último de esta infinitud se aclarará más adelante. Por lo pronto comencemos con la cuestión de su nombre. 'Ouotouk@̃̃ es el término con el que casi siempre se designan en el Corpus aristotélico. Con todo, es muy dudoso, si no es que enteramente falso, el que Anaxágoras les haya dado tal nombre. En varios lugares de su obra, el mismo Aristóteles así parece dejarlo entrever. ${ }^{30}$

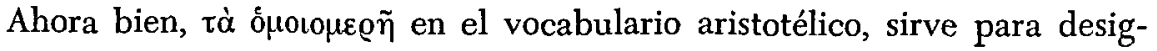
nar en ocasiones a los cuerpos compuestos ( $\tau \dot{\alpha} \mu \mu x \tau \dot{\alpha} \sigma \omega ́ \mu \alpha \tau \alpha)$ de los cuatro elementos simples - Fuego, Aire, Tierra y Agua-, o más precisamente de las cuatro cualidades simples - Calor, Sequedad, Frío y Humedad_-31 Tal calificativo lo reciben en virtud del hecho de que por división simple nunca cesan de ser lo que son. Sus partes retienen siempre, por lejos que llevemos tál tipo de división, el mismo carácter o las mismas propiedades, del todo. ${ }^{32}$ Son, para decirlo en una palabra, ómoเọєeñ. Dada esta condición, y supuesto que el cuerpo $(\sigma \tilde{\omega} \mu \alpha)$ es divisible al infinito, ${ }^{33}$ es fácil ver que incluso las partes de un todo se comportan, al ser divididas, de idéntico modo que él. ${ }^{\mathbf{3 4}}$ Ejemplos de estos cuerpos son los metales, la madera, el hueso, la médula, la carne, la sangre, etc. ${ }^{35}$ Pero, por otra parte, los elementos también pueden ser designados de la misma suerte, pues es obvio que sus partes tienen y conservan las mismas propiedades que cada uno de ellos; ${ }^{30}$ si bien puede

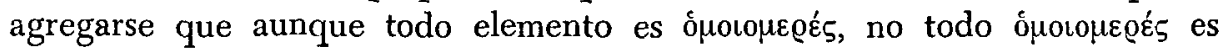

314a 24-29; Metaph., A, 6, 988a 27-28. Cf. Aecio I, 3, 5; I, 7, 5; Lucret., de rerum naturae, I, 834.

29 Véase Arist., phys., A, 4, 187a 22-26; A, 5, 188b 15-17; $\Gamma, 4$, 203a 19-21; de gen. et corr., A, 1, 314a 16-18; Metaph., A, 3, 984a 11-13. Cf. Pseudo-Arist., de Melisso Xenophane et Gorgia, 2, 975b 17-18; Simpl., phys., 27, 2; 155, 23; 460, 4; Hipolit., Refut., I, 8, 1; Cic., Acad. Pr., II, 37, 118.

30 Cf. H. Cherniss, Aristotle's criticism of Presocratic philosophy, The John Hopkins Press, Baltimore, 1935; págs. 2-3.

31 Arist, de anima, $\mathrm{B}, 11,423 \mathrm{a} 13$; de gen. et corr., B, 7, 334b 30-335a 9. Cf. Arist., de caelo, $\Gamma, 3,302 \mathrm{a} 21 ; \Gamma, 7,306 \mathrm{~b} 1$. Véase Ingemar Düring, Aristotle's Chemical Treatise (Meteorologica, Book IV), Wettergren \& Kerbers Förlag, Göteborg, 1944; págs. 14-15, y Thomas East Lones, Aristotle's Researches in Natural Science, West, Newman \& Co., London, 1912; págs. 90-91.

32 Sobres la idéntica aplicación de las propiedades al todo (oóvokov) y a sus partes, véase Arist., Top., E, 5, 135a 20-135b 6.

33 Arist., de caelo, A, 1, 268a 7-9. Cf. Arist., phys., Z, 2, 232b 24; Z, 8, 239a 22; de gen. et corr., A, 10, 328a 5-6; de caelo, $\Gamma, 8,306 \mathrm{~b} 22$.

34 Véase Arist., de caelo, $\Gamma, 3,302 \mathrm{~b}$ 15. Este texto muestra claramente que cada

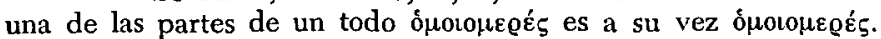

35 Véase Bonitz, Index Aristotelicus, ed. Acad. Regia Boruss., Reimer, Berolini, 1870; pág. 510b 34-42, e Ingemar Düring, op. cit., págs. 97-98.

30 Véase Arist., Metaph., A, 9, 992a 6-7. Cf. Arist., de gen. et corr., A, 10, 328a 10-11; Top., E, 5, 135a 32-135b 6. 
elemento. ${ }^{37}$ La razón de ello es bien visible. Un cuerpo compuesto sujeto a una división analizadora, y no meramente simple, se disgregaría en constituyentes que no tendrían la misma forma ( $\varepsilon^{i} \delta \circ 5$ ) que el compuesto, ${ }^{38}$ y sus componentes, los elementos que constituyen su materia, saldrían a la luz al separarse. $^{39}$ Un elemento, por lo contrario, sea que lo dividamos de modo simple o analítico, nunca podrá descomponerse en partes que sean distintas por la forma que él..$^{40}$ Lo que permite distinguir a unos y otros es, pues, el

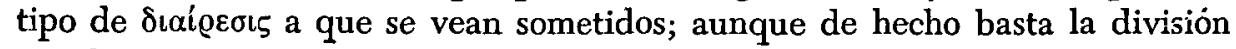
simple, tal como puede verse por lo ya dicho, para decidir acerca de si algo

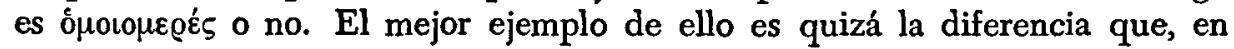
virtud de tal división, se establece entre los órganos y los tejidos. Todo cuerpo viviente es $\sigma \tilde{\mu} \mu \alpha$ ỏopavıóv. Los órganos tales como, por ejemplo, un ojo o

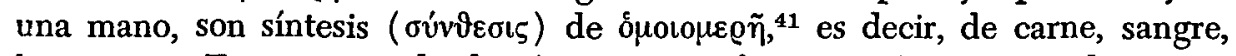

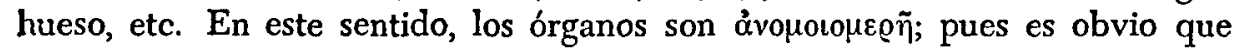
la parte de una mano no es mano a su vez; no conserva el mismo carácter del órgano entero. ${ }^{42}$

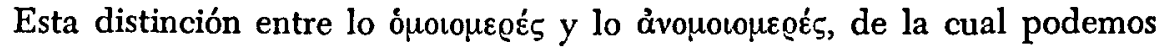
encontrar el anticipo en el diálogo platónico Protágoras, ${ }^{43}$ es la base para interpretar los testimonios aristotélicos acerca de la doctrina de Anaxágoras sobre las simientes. Hemos ya dicho que es bastante verosímil que tales testimonios estén viciados desde su raíz misma. En efecto, si estas simientes, en cuanto componentes últimos de la realidad, representan lo que Aristóteles podía denominar "elementos" y ofrecían rasgos de lo que para él era lo ó $\mu \circ \mu_{\mu} \varepsilon \varepsilon \varepsilon \xi$, eso no

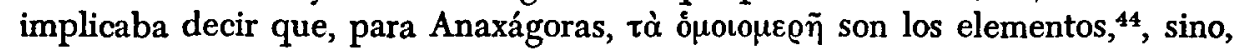
a lo más, el poner de relieve que, eso que de acuerdo con su propio punto

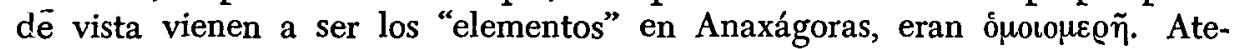
niéndonos, pues, a la terminología y al pensamiento de Aristóteles, se pueden

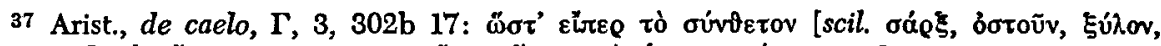

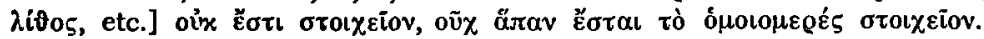

38 Arist., de gen. et corr., A, 5, 321b 21-22. Sobre esto véase H. H. Joachim, op. cit., págs. 129-130.

39 Arist., de caelo, $\Gamma, 3,302 \mathrm{a} 21-23$.

40 Arist., de caelo, $\Gamma, 3,302 \mathrm{a}$ 16-19. Cf. Arist., de caelo, $\Gamma, 4,302 \mathrm{~b}$ 19-20.

41 Arist., de gen. et corr., A, 5, 321b 16-19. Sobre todo esto véase Ingemar Düring, Aristotle's De Partibus Animalium. Critical and Literary commentaries, Wettergren \& Kerbers Förlag, Göteborg, 1943; pág. 126.

42 Arist., de gen. et corr., A, 5, 321b 28-29.

43 Plat., Prot., 329d-e. Platón distingue dos modos de ser de las partes. Hay partes, como, por ejemplo, las partes de una masa de oro, que no difieren del todo ni una de la otra. En cambio, hay otras, como las partes de la cara: boca, nariz, ojos, etc., que no son iguales entre sí, ni iguales al todo. El primer modo es un buen ejemplo, de lo que,

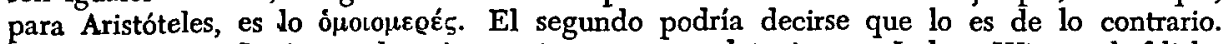
Véase Fr. Ast, Lexicon platonicum sive vocum platonicarun Index, Wissenschaftliche Buchgesellschaft, Darmstadt, 1956; vol. II, págs. 362-363.

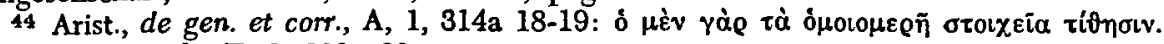
Cf. Arist., de caelo, $\Gamma, 3,302 \mathrm{a} 32$. 
considerar las simientes, sin perjuicio de la objetividad, bajo el aspecto de aquello cuyas partes son iguales en nombre y naturaleza que el todo. ${ }^{45} \mathrm{~A}$ esto podríanse agregar todavía otras dos determinaciones. Aristóteles nos dice,

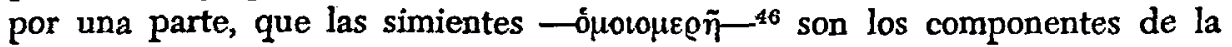
realidad entera $y$, por otra, que nunca pueden darse en estado de pureza. ${ }^{47}$ El último punto es de no poca importancia, ya que a partir de él se aclararán, como veremos, muchas cuestiones relativas tanto al pensamiento de Anaxágoras, como a su interpretación por parte de Aristóteles. En cuanto a su legitimidad, no creemos que pueda caber ninguna duda. En repetidos sitios, Aristóteles al hablar de las simientes las ejemplifica preferentemente como hueso o carne..$^{48}$ Ahora bien, en la Física nos dice que, para Anaxágoras, no hay nada que sea del todo y puramente carne o hueso.49 Esto implica la imposibilidad de aislar las simientes las unas de las otras; puesto que una simiente aislada sería total y puramente hueso o carne, para poner los mismos ejemplos de Aristóteles. La expresión de dicha imposibilidad la veremos más adelante en los fragmentos del propio Anaxágoras; pero por lo pronto establezcamos ciertas consecuencias. En primer lugar, dado que las simientes no pueden darse nunca en la realidad, por no poder ser aislables en estado de pureza, ello quiere decir que no se identifican sin más con las partes separables de una cosa cualquiera, $y$, en segundo lugar, dado que, según lo postula Anaxágoras, en todo, esto es, en todas las cosas, hay una porción de todo, ${ }^{50}$ no se puede decir que en las simientes haya una porción de todo. Este rasgo es justamente lo que las distingue de las cosas, ${ }^{51}$ e implica necesaria-

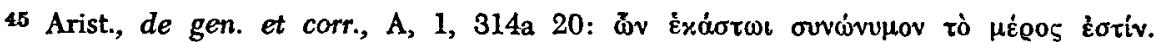

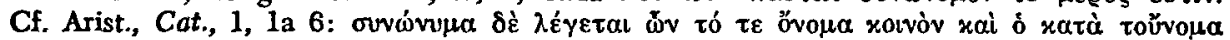

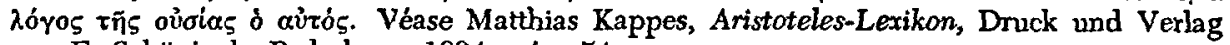
von F. Schöningh, Paderborn, 1894; pág. 54.

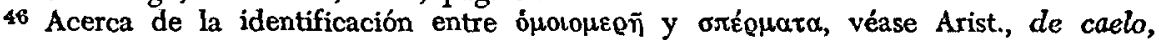
Г, 3, 302a 32-302b 2.

47 Arist., de gen. et corr., A, 1, 314a 25-314b I; de caelo, $\Gamma, 3,302 \mathrm{~b} 2-3$.

48 Arist., de gen. et corr., A, I, 314a 27: ... ox́ex $\alpha$ rai óotoũv. ..; de caelo, $\Gamma, 3,302 \mathrm{a}$

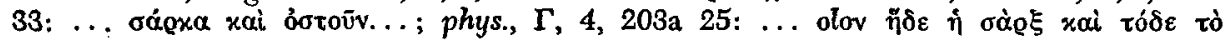

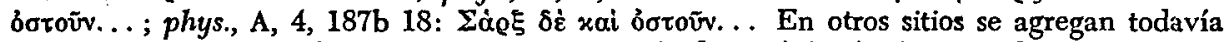

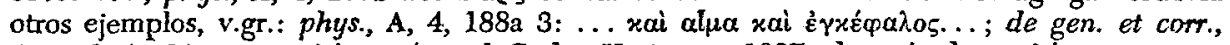

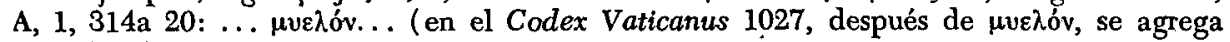

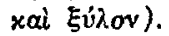

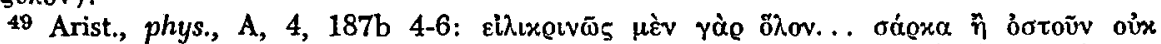

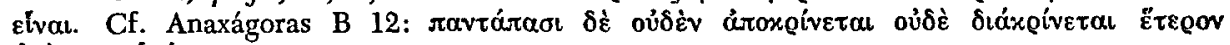

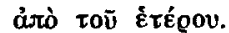

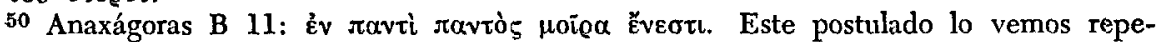
tirse constantemente en los fragmentos de Anaxágoras. Cf. Arist., phys., $\Gamma, 4$, 203a 23-24:

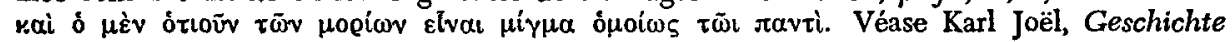
der antiken Philosophie, J. C. B. Mohr, Tübingen, $1921 ; 1$, pág. 574.

51 La suposición de que en las simientes hay una porción de todo, tanto como en las cosas, tiene presumiblemente su origen en Simplicio. En Simpl., phys., 460, 4, leemos,

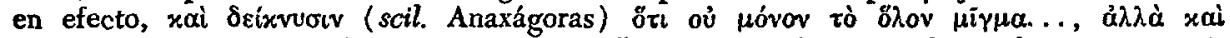

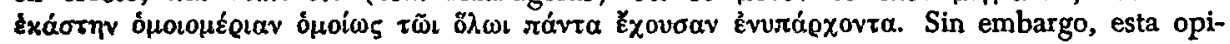


mente el que nunca puedan darse en cuanto tales, aisladamente, en un cos-

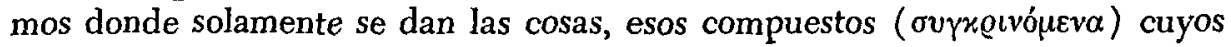
ingredientes últimos e inseparables son las simientes. ${ }^{52}$

Si Aristóteles se hubiera concretado a decirnos esto, no habría hecho más que exponer -bien es cierto que con ayuda de sus propias palabras y ejemplos- una parte de la doctrina de Anaxágoras. Pero cuando pasa a criticarla a partir de su pensamiento propio, llega a consecuencias que no concuerdan con la tesis de que las simientes, por no poder darse en estado de pureza, puedan separarse de las cosas que componen. El hecho es muy explicable. Las simientes, tal como él las considera, vienen a ser los elementos, los ingredientes, de los compuestos. Cada uno de éstos, según Anaxágoras, se presenta con el carácter que tiene a causa de que en él predominan las simientes que corresponden a tal carácter ${ }^{53}$ Esto a Aristóteles le parece que implica algo que no se aviene con la función de los elementos. Pues, en efecto, si la predominancia de un elemento caracterizara al cuerpo compuesto, ello querría decir que los elementos persisten como tales en el compuesto, es decir, que se encuentran en él actualmente y no potencialmente, tal como sería necesario que se encontraran en el caso de tratarse de un verdadero compuesto. ${ }^{5 *}$ De aquí que Aristóteles interprete el postulado de Anaxágoras de que en todo hay una porción de todo, como si en todo, estuviera todo presente no potencialmente, sino actual y separadamente..$^{\check{z}} \mathrm{Si}$ ello es así, las simientes podrán ser separadas a la larga de las cosas, puesto que cada una de ellas no será verdadero $\mu \tilde{\gamma} \gamma \mu \alpha$, sino oúvษerov. ${ }^{56}$ Es claro que el auténtico pensamiento de Anaxágoras no es éste; pero tal interpretación de Aristóteles es muy comprensible dentro del contexto de su propia filosofía.

Lo es también la razón del por qué Aristóteles ha denominado a las si-

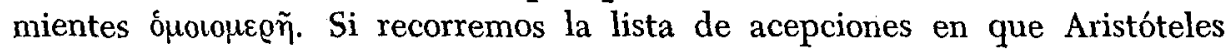
toma el término, comprobaremos que las simientes, supuesto que como ele-

nión, comúnmente aceptada, no es sino una mala interpretación del texto aristotélico comentado; pues Aristóteles, cuando nos dice (phys., $\Gamma, 4,203 a$ 23-24): xai ó $\mu$ غ̇̀ ó $\tau$ )

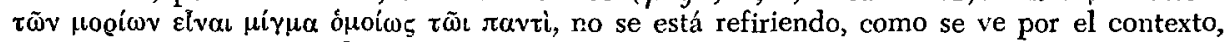
a los ó $\mu$ o $о \mu \varepsilon \varrho \tilde{\eta}$, sino a las partes de la realidad entera, las cuales, como ésta, son una mezcla de todos los componentes últimos, es decir, de todas las simientes.

52 Véase Anaxágoras B 8. El conjunto de las cosas es evidentemente lo que Anaxágoras denomina el "cosmos uno".

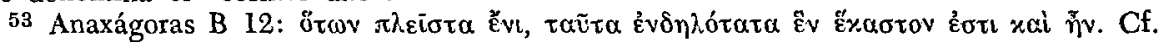
Arist., phys., A, 4, 187b 6-7.

54 Cf. Arist., a ge gen. et corr., A, 10, 327b 23-33; de caelo, 3, 302a 21-23.

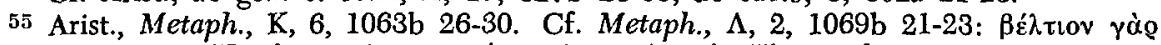

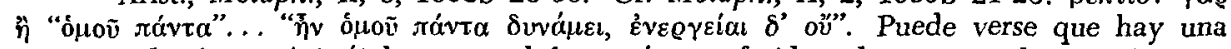
cierta confusión en Aristóteles entre el óuoṽ jóvia referido a las cosas, tal como éstas se encontraban en la mezcla originaria, y el referente a las simientes, tal como éstas se encuentran siempre en las cosas.

50 Arist., phys., A, 4. 187b 7-188a 5. 
mentos son consideradas, ${ }^{57}$ sólo pueden recibir tal calificativo a la manera en que lo reciben los elementos aristotélicos. Esto, aparte de las otras razones bien evidentes que en su favor podrían alegarse, se torna más plausible si recordamos que en el primer libro de la Metafísica, Aristóteles compara dicho carácter de las simientes con el del agua y el fuego. En la misma forma en

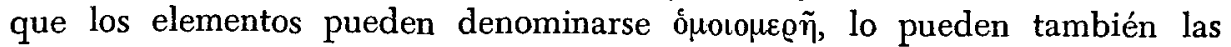
simientes. ${ }^{58}$ Atiéndase, por otra parte, al hecho de que Aristóteles confunde estas últimas con las cosas que se encuentran en la mezcla primitiva y que por separaciones progresivas dan origen a otras, ${ }^{59}$ concibiéndolas como partes separables, ${ }^{60}$ y será posible formarse una idea completa del porqué de la

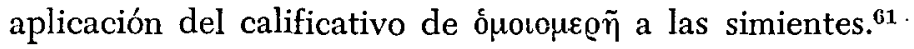

Más difícil, y quizá imposible de resolver es la cuestión relativa a los

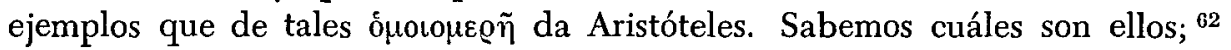
pero lo cierto es que en los fragmentos de Anaxágoras no es posible encontrar nada parecido. ${ }^{63}$ Antes bien, los ejemplos que encontramos de algunas de las

57 Véase $n .44$.

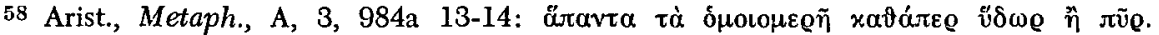
Como lo ha hecho notar Bonitz, xavớree no significa aquí "como por ejemplo", sino más

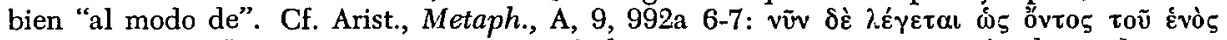

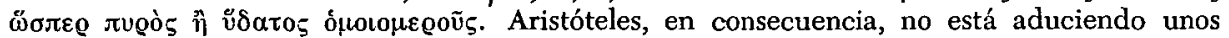

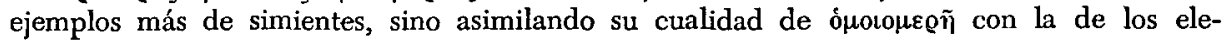
mentos.

59 Véase $\mathrm{n} .55$.

60 Arist., phys., A, 4, 188a 15-17; de gen. et corr., B, 7, 334a 35-334b 3. Véase n. 55. Aristóteles interpreta, como consecuencia de tal composición, la mezcla de simientes en una cosa como una síntesis relativa a la percepción. Véase Arist., de gen. et corr., A, 10,328 a $12-15$.

61 Algo parecido podemos encontrar en Aecio, I, 3, 5 (Anaxágoras A 46): ảiò นoũ

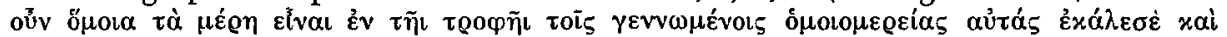

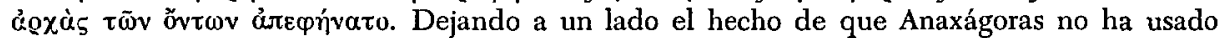
tal término, así como todo lo que esto implica relativo a la nutrición, obsérvese que Aecio hace resaltar el hecho de la igualdad de naturaleza de las partes contenidas en dos cosas distintas como causa del nombre que recibe. Cada una de las cosas, por otra parte, es una mezcla ( $x \varrho \tilde{\sigma} \sigma ı \zeta)$ de estas partes, simientes o elementos; cf. Aecio, I, 17, 2 (Anaxágoras A 54).

62 Véase n. 48.

63 El fragmento décimo de Anaxágoras no constituye una prueba, en el caso de que sea auténtico, de que Anaxágoras haya considerado a la carne y al pelo como simientes. El escoliasta de Gregorio Nacianceno, a quien debemos la cita, está visiblemente influído por la interpretación que hace Simplicio, en phys., 460, 16, de Arist., phys., $\Gamma, 4,203$ a 24 :

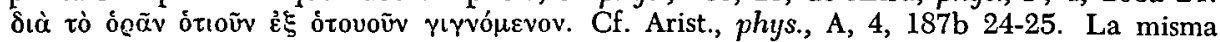
cuestión respecto a la igualdad de ingredientes entre la nutrición y lo nutrido, que el escoliasta aplica al crecimiento del embrión (yoví), podemos encontrarla también en Aecio I, 3, 5. El valor de todos estos testimonios deriva, pues, del valor que pueda tener el testimonio aristotélico acerca de que la carne, el hueso, etc., son simientes para Anaxágoras. En consecuencia, es una petitio principii apoyarse en ellos para probar la interpretación de Aristóteles. Hasta qué punto depende este nuestro escoliasta de Aristóteles, podremos verlo si comparamos la interrogante -omitida en la 
infinitas simientes predominantes son el calor, el frío, lo denso, lo raro, lo oscuro, lo brillante, lo húmedo y lo seco, ${ }^{64}$ esto es, parejas de contrarios y no otra cosa. Esta dificultad ha dado lugar a un sinnúmero de controversias que cobran un gran ímpetu a partir de los estudios de Breier ${ }^{65}$ sin que aún hoy se haya llegado a conclusiones definitivas. A nosotros nos parece - sin que con esto pretendamos solucionar la cuestión de una vez por todas- que la razón de tal divergencia debe buscarse en la interpretación y crítica que Aristóteles bace de la filosofía de Anaxágoras. Esto es, afirmamos que cuando Aristóteles pone semejantes ejemplos de las simientes, se deja llevar por su propia interpretación, sin atenerse al auténtico pensamiento de Anaxágoras; a lo cual sin duda ha contribuído la oscura expresión de éste. ${ }^{66} \mathrm{Si}$, reparamos, en efecto, en que para Aristóteles los cuerpos compuestos tienen un carácter muy distinto que el de sus componentes y en que, según él mismo, las cosas de que Anaxágoras habla tienen el carácter que tienen a causa de la predominancia de partes elementales con ese idéntico carácter, dadas, pues, no potencial sino actualmente, si reparamos en esto, repetimos, será fácil comprender el que Aristóteles al contraponer su propia teoría con la de Anaxágoras supusiera que, por ejemplo, la carne es tal a causa de que en ella predominan las partículas de carne sobre la infinita variedad de las demás simientes. ${ }^{67}$

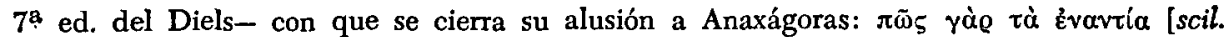
lo negro, lo blanco, lo pesado y lo liviano] toïs évavtiols ouvéoovtal (Migne, Patrologia Graeca, XXXVI, pág. 911); con Arist., Metaph., A, 8, 989b 2-11, y phys., A, 4, 188a 12-13. 64 Anaxágoras B 4; B 8; B 12; B 15.

65 Nos referimos al libro de Breier, Die Philosophie des Anaxagoras von Klazomenae nach Aristoteles, publicado en Berlín en 1840.

60 Jean Zafiropulo, Anaxagore de Clazomène, Les Belles Lettres, Paris, 1948; pág. 281, nos dice, refiriéndose a los testimonios aristotélicos sobre Anaxágoras: "son prestige fut tel que, par la seule force de son affirmation, il paroint à imposer totalement le fruit de son étude... superficielle en contradiction pourtant flagrante avec les écrits mêmes d'Anar xagore".

67 Idéntico es el caso del agua. En ésta también hay una porción de todo; sólo que lo que en ella predominan son las partículas de agua y no las de carne. Véase Arist.,

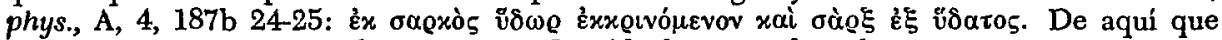
Aristóteles nos diga que lo que para Empédocles eran los elementos, para Anaxágoras

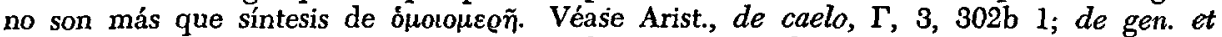
corr., A, 1, 314a 24-314b 1. Ahora bien, lo que Aristóteles nos dice en Metaph., A, 3,

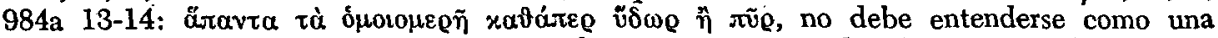
ejemplificación más de las simientes, por las razones ya citadas (véase $n$. 58). Sin embargo, es evidente que incluso el agua y el fuego pueden valer, para Aristóteles, como ejemplos de simientes, tal como se ha dicho al principio de esta nota. Esto mismo es lo

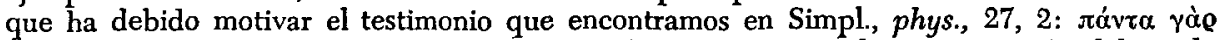

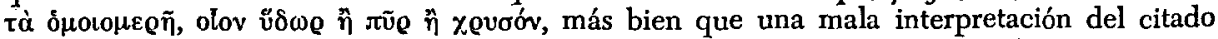
texto de la Metafísica, como lo supone Ross, Aristotle's Metaphysics, Clarendon Press, Oxford, 1948; I, pág. 133; pues inmediatamente después de esto, Simplicio nos habla de la predominancia de ciertas simientes como causa del carácter de tal cosa determinada -en la que se dan al par todas las demás-. En este sentido, el agua y el fuego son tan buenos ejemplos de partículas predominantes como el oro con el que Simplicio ilustra esta tesis, $y$ al cual pone, como se ve por sus palabras, en la misma condición que el 
Acerca de cuál haya sido la verdadera doctrina de Anaxágoras sobre este punto, no es fácil formarse una idea clara, debido al número tan pequeño de fragmentos que de su obra poseemos; pero es patente, por lo menos, el hecho de que Anaxágoras, para quien los sentidos no merecen ninguna confianza, ${ }^{68}$ muy difícilmente hubiera podido concebir la realidad de este modo tan tosco.

Aristóteles, por otra parte, no ha dejado de reconocer que los contrarios ocupan el mismo puesto que los ónolopkõ̃ en la filosofía de Anaxágoras. Así nos lo dice en varios lugares. ${ }^{69}$ Pero, no obstante, los ejemplos que de ellos aduce no concuerdan con los de Anaxágoras. ${ }^{70}$ Esto nos indica que Aristóteles no ha dejado de reconocer que había una cierta divergencia entre su interpretación y la doctrina auténtica de Anaxágoras. Sobre esta cuestión, por lo tanto, los testimonios aristotélicos no pasan de ser una mera interpretación, y como tal deben tomarse, sin concederles el rango de una exposición objetiva. y fiel. Sin embargo, así como el conjunto de tales testimonios no puede considerarse como una exposición apegada a la autenticidad de la filosofía de Anaxágoras, tampoco puede decirse que sea una pura interpretación. Por lo contrario, menester es ante todas cosas hacer un deslinde entre lo que ahí se da de meramente expositivo y de interpretativo, esto es, hacer una crítica de los testimonios aristotélicos sobre Anaxágoras. El único camino para lograrlo deberá seguir, como es obvio, el hilo conductor que brinda la comparación de estos testimonios con los fragmentos que de Anaxágoras poseemos. Sólo de esta manera, nos parece, podrán aclararse tanto los unos como los otros. ${ }^{71}$

Dirigiendo ahora nuestra atención a las propias palabras de Anaxágoras, será relativamente fácil ahondar en el resto de la temática que de un modo u otro se relaciona con su tesis de la indestructibilidad de lo que es. Más atrás hubimos de ver la forma en que Anaxágoras explicaba el verdadero mecanismo de la generación y la destrucción. El repudio de todo lo que pudiera implicar la menor aceptación de lo que no es ha sido la base donde Anaxágoras viene a sustentar las líneas generales de su doctrina al respecto. Pero de este pensamiento fundamental se desprenden todavía más consecuencias.

agua y el fuego. Algo idéntico encontramos también en Filoponio, de gen. et corr., 13, 26 y en Lucrecio, I, 840-841.

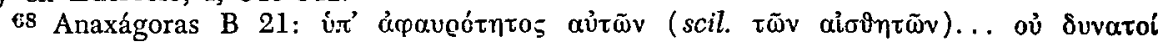

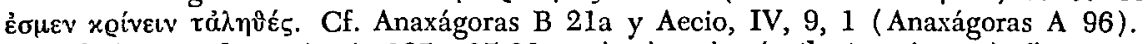

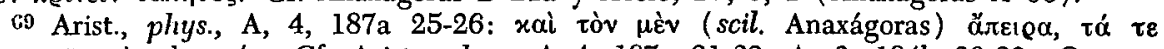

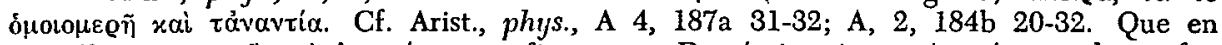
este último texto $\mathfrak{\eta}$ xai ह̉vavtías se refiere no a Demócrito sino a Anaxágoras, lo confirman Temistio, in Arist. phys., 3, 1: Filoponio, in Arist. phys., 26, 8 y Porfirio, comm. in Arist. phys., 44, 1.

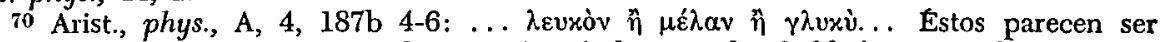
los ejemplos de esos contrarios de que Aristóteles nos ha hablado pocas líneas atrás. Véase n. 69.

71 Para un panorama de los principales intentos de reconstrucción de la doctrina de Anaxágoras, véase Cyril Bailey, The Greek atomists and Epicutrus, Clarendon Press, Oxford, 1928; págs. 537-545. 
Consecuencias que vendrán a especificar y a aclarar aún más dicha doctrina. La que en primer término vamos a tratar viene a ser, tanto como las otras, una mera repercusión de lo que ya se nos ha hecho presente en el pensamiento de Parménides y en el de Empédocles: la imposibilidad de que la realidad pueda sufrir un aumento. Esta, para Anaxágoras, es el conjunto de todas las cosas y, por lo tanto, sería un absurdo creer que las cosas pueden llegar a ser más que su conjunto. Lo mismo vale para el caso opuesto. Tampoco puede suceder que algo desaparezca por completo; pues eso supondría la destrucción absoluta de una parte de la realidad. Esta, consecuentemente, es siempre igual a sí misma; no aumenta ni puede disminuir. ${ }^{72}$

De aquí deriva la posibilidad de un empequeñecimiento progresivo e infinito de las cosas; puesto que por lejos que éste vaya, nunca podrá desaparecer lo que va disminuyendo de tamaño. Es imposible que lo que es pueda no ser absolutamente. ${ }^{73}$ Por pequeña que sea una cosa siempre podrá ser menor, sin que haya un límite que lo impida. ${ }^{74}$ Ahora bien, si por una parte se afirma que las cosas no pueden destruirse de modo total en este proceso, por la otra resulta que tampoco pueden perder su carácter de cosas $(\chi \varrho \tilde{\eta} \mu \alpha \tau \alpha)$.

La cabal comprensión de esta última afirmación es ciertamente importante. En un cierto sentido podría decirse que ella constituye el meollo de la filosofía de Anaxágoras; pero hay algo más. Las tesis que, gracias a diversos testimonios, conocemos acerca de lo que este filósofo pensaba en torno al vacío, adquieren únicamente plenitud de sentido vistas sobre el trasfondo de esta cuestión. De aquí la necesidad en que nos vemos de tratar ciertos asuntos que en rigor no caen dentro del ámbito de esta investigación.

Comencemos por establecer ciertos hechos. En todas las cosas, como repetidamente sostiene Anaxágoras, hay una porción de todo y, por consiguiente, puede decirse que en todas ellas, sean grandes o pequeñas, hay una misma cantidad de porciones cualitativamente distintas; puesto que en todas hay una porción de cada una de las infinitas cualidades, ${ }^{75}$ si bien es cierto por otra parte, que en cada cosa predomina aquella cualidad que le da el carácter que tiene, tanto como el que ha tenido. ${ }^{76} \mathrm{Y}$, en este sentido, las cosas

72 Anaxágoras B 5.

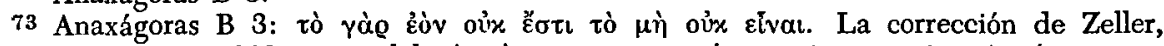

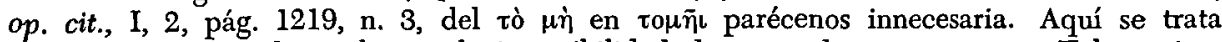
de algo más general que la simple imposibilidad de cesar de ser por corte. Tal enmienda, sugerida por Lucrecio, I, 844, no vendría, pues, sino a proponer uno de los casos especiales de esta tesis. Obsérvese, por otra parte, que la redundancia de la negación indica suficientemente que aquí no se trata de un no ser relativo, sino absoluto.

74 Anaxágoras B 3.

75 Anaxágoras B 6. Cf. Anaxágoras B 3.

76 Anaxágoras B 12. Atendiendo al sentido del contexto entero es muy probable,

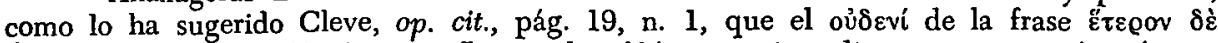

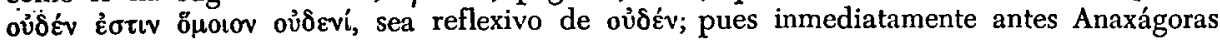


diferirán las unas de las otras de acuerdo con las diferentes cualidades que en ellas predominen. ${ }^{i \tau}$ Por lo dicho puede colegirse que hay una correspondencia muy estrecha entre tales porciones y las simientes. En realidad, es legítimo considerarlos como equivalentes. En los fragmentos de Anaxágoras, así como en los testimonios a él referentes, no hay nada que impida hacerlo y sí mucho que viene a confirmarlo.

Supongamos ahora que una cosa, en la que se da como dominante una cualidad, vaya empequeñeciendo progresivamente, ¿significará esto que poco a poco se van separando de ella esas porciones cualitativamente distintas que contiene y que puede llegar el momento en que no quede más que una sola porción aislada? Anaxágoras piensa todo lo contrario. ${ }^{78}$ Las cosas no dejan de ser cosas, esto es, compuestos, por pequeñas que sean. La grandeza y la pequeñez no afectan, en consecuencia, su carácter. Son meros conceptos que surgen por comparación de las cosas entre sí; puesto que consideradas éstas en sí mismas, sin compararlas con otras, son tanto grandes como pequeñas. ${ }^{79}$ Grandes lo son sólo en comparación con algo menor y viceversa. El proceso de empequeñecimiento es, pues, infinito: siempre podrá haber algo menor,

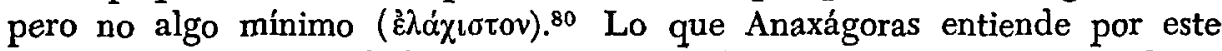
"mínimo", es bien fácil de descubrir. A lo "mínimo" — nos dice— no le es posible ser, puesto que no podría ser aislado ni llegar a ser separadamente

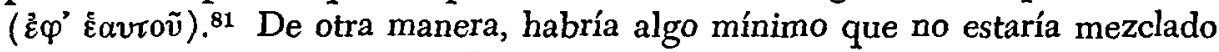
con nada, solo y en estado de pureza. No otra cosa significa la expresión

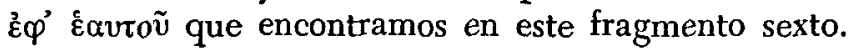

Las traducciones habituales pasan por alto este hecho tan simple; pero si comparamos lo anterior con lo que Anaxágoras nos dice tocante al Nous, se hace evidente que $\hat{\varepsilon}^{\prime}{ }^{\prime} \varepsilon \alpha v \tau o \tilde{u}$ no viene a ser más que lo contrario de ónoũ. El Nous, en efecto, no se mezcla con nada, sino que existe solo y separadamente. $^{82}$ No contiene, como las cosas, una porción de todo. En esto

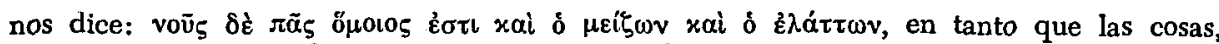
las grandes así como las pequeñas, no son iguales en sí mismas, no encierran solamente la cualidad que las caracteriza, sino también todas las demás.

77 Anaxágoras B 4. Es claro, además, que el predominio de determinada cualidad en una cosa no viene a ser más que consecuencia del mayor número de porciones de semejante cualidad, en comparación con el número de las que de otras haya. De otro modo no se explican los plurales que encontramos en Anaxágoras B 12: ö $\tau \omega v \pi \lambda \varepsilon i \sigma \tau \alpha$ है है

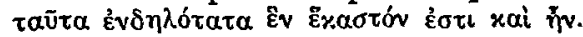

78 Cf. Arist., Metaph., K, 6, 1063b 26-30; Metaph., $\Lambda, 2,1096 \mathrm{~b}$ 21-23. phys., A 4, 187b 7-188a 17.

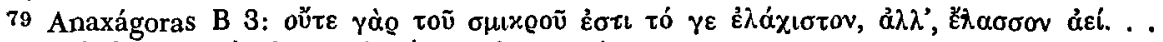

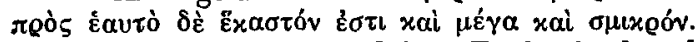

80 Anaxágoras B 3. Véase Erich Frank, Plato und die sogenannten Pythagoreer, Max Niemeyer, Halle, 1923; pág. 50.

81 Anaxágoras B 6.

82 Anaxágoras B 12. Véase, por otra parte, la reveladora contraposición que se hace,

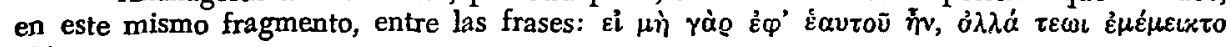
à $\lambda \lambda \omega \boldsymbol{c o t} .$. 
se asemeja a las simientes; sólo que así como el Nous puede darse en un mundo donde no hay más que cosas, compuestos, las simientes no lo pueden. Estas, al igual que estuvieron antes de que las cosas comenzaran a separarse, están siempre juntas. ${ }^{83}$ En la realidad no hay simientes puras, sino sólo mezcla de ellas. Aristóteles entendió en parte, como vimos más atrás, que esto era así. Pero igualmente revelador es el comentario que hace Simplicio de la

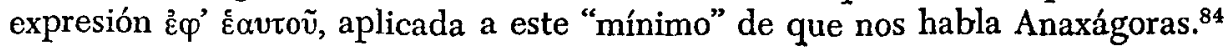
Tal nombre sugiere de modo muy adecuado el doble carácter que presentaría una simiente pura y sin mezcla, supuestamente aislada. Pues, por un lado, lo "mínimo" no es cosa, dado que toda cosa puede ser siempre menor de lo que es; pero tampoco es no ente: es la mínima realidad pensable.

Con todo, aunque en términos generales nada de lo que no contiene una porción de todo está separado o dividido absolutamente, excepto el Nous, ${ }^{85}$ puede decirse que las simientes, en cierto sentido, están separadas las unas de las otras. No hay, pues, una separación completa; pero sí una peculiar clase de separación de las simientes: ${ }^{86}$ aquélla que se efectúa por obra y gracia de la razón ( ó $_{05}$ ) y que no viene a ser más que una distinción meramente conceptual, de acuerdo con las diferencias cualitativas de las simientes. Bajo esta consideración, puede decirse que hay el mismo número de partes "separadas", en lo grande y lo pequeño, ${ }^{87}$ aunque en la realidad, en el cosmos uno, las simientes no estén separadas de modo tajante, como por el golpe de un hacha. ${ }^{88}$ Pero si la razón es capaz de efectuar tal distinción, sus capacidades no llegan a tanto que pueda conocer el número de las simientes. Su variedad es infinita e incognoscible. ${ }^{89}$

Ahora bien, el hecho de que las cosas, cada una de las cuales es, como ya nos lo decía Aristóteles, una panspermia, ${ }^{00}$ se den separadamente las unas

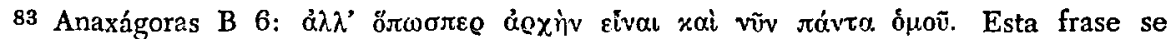
refiere evidentemente a las simientes y no a las cosas; pues aunque en el fragmento pri-

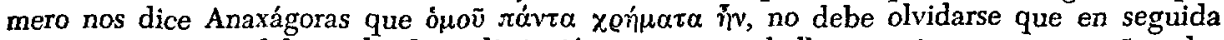
se separan y que del estado de indistinción en que se hallan gracias a su pequeñez devienen o llegan a ser distinguibles. Y más tarde, gracias a posteriores separaciones, se originan "las cosas que ahora son entre los hombres" (Anaxágoras B 9), el agua, la tierra, las piedras, etc. Véase Anaxágoras B 15 y B 16.

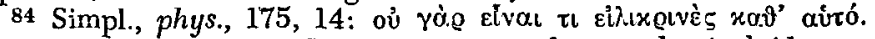

85 Anaxágoras B 12. Las cosas no pueden quedar incluídas en esta afirmación, pues en relación a ellas esto no tendría otro sentido que el de una negación del vacío. Pero quedaría el problema de que el Nous, por estar separado, debería implicar la existencia de ese mismo vacío; resultado que no concuerda con la doctrina de Anaxágoras. Esto, más bien, refuerza la presunción de que el Nous y las simientes comparten la característica de no tener una parte de todo y pueden, por ello, ser comparados para hacer resaltar aquello en que difieren.

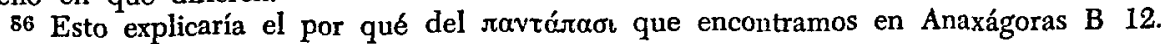

87 Anaxágoras B 6.

88 Anaxágoras B 8.

89 Anaxágoras B 7.

90 Arist., de gen. et corr., A, 1, 314a 29; de caelo, $\Gamma, 4$, 303a 16 phys., $\Gamma, 4$, 
de las otras en un momento posterior a aquel en que todas estaban juntas, ${ }^{91}$ no significa que estén separadas por un hiato de irrealidad, por un vacío en que no hubiera cosa alguna. Más bien, esta separación no tiene otra índole que la de una separación de acuerdo con determinadas cualidades predominantes de las cosas. Una cosa está separada de otra que le es próxima, espacialmente hablando, cuando sus cualidades predominantes no son iguales en las dos, sino diferentes. Es en esta forma probablemente como deben entenderse esas mezcla y separación en que consisten lo que equivocadamente se denomina generación y destrucción, pues no debe olvidarse que se trata de mezcla y separación de cosas y no de simientes, aunque el mecanismo más profundo de tales procesos nos queda desconocido. Sin embargo, sea éste el que fuere, no por ello es menos cierto que, para Anaxágoras, ningún género de separación puede implicar un vacío en que no haya cosas. Pues, si la separación no consiste más que en un movimiento, éste no presupone en forma alguna el vacío. ${ }^{92}$ La ausencia de una cosa es la presencia de otra: el "sitio" que la primera va dejando va siendo ocupado por la segunda. Tal tesis Anaxágoras no se contentará con sentarla sin más pruebas, o como un mero postulado, sino que, por el contrario, procurará demostrarla de modo experimental, en una forma que para su tiempo es de un rigor extraordinario. Cosa semejante ha llevado a efecto Empédocles, y de las experiencias de estos filóssofos resultarán consecuencias que no sólo son aplicables a la realidad entera, sino a diversos problemas muy concretos, especialmente biológicos. Aplicaciones que la medicina griega habrá de aprovechar e incorporar dentro de sus concepciones, tal como habremos de verlo más adelante.

\section{Adolfo García Díaz}

203a 21. No es seguro que tal término haya pertenecido al vocabulario de Anaxágoras. Platón lo emplea en el sentido de siminum omnis generis cinnus. Véase F. Ast, op. cit., vol. III, pág. 22. 81 Anaxágoras B 1. Véase n. 83.

92 Véase Pseudo-Arist., de Melisso Xenoph. et Gorgia, 976b 21-22. 